\title{
Esferas de visibilidade jornalísticas e relações de poder: um estudo sobre a memória do Oeste catarinense na imprensa nacional e regional (1940-1950)
}

\author{
Marcionize Elis BAVARESCO ${ }^{1}$ \\ Carlos LOCATELLI ${ }^{2}$
}

\begin{abstract}
Resumo:
Este trabalho analisa como a região Oeste de Santa Catarina, Brasil, foi retratada na imprensa regional e nacional a partir de dois fatos noticiosos ocorridos em 1948 e 1950. Ambas as coberturas (sobre o contrabando de madeira e sobre um linchamento) tratam de temas que colocam em confronto perspectivas de ordem, progresso, atraso e marginalidade. As esferas de visibilidade do jornalismo são aqui compreendidas no plural, com foco em duas delas: a do jornalismo de proximidade e aquela baseada no jornalismo de distanciamento. A base teórico-metodológica da pesquisa combina a análise documental, bibliográfica e de conteúdo. A principal conclusão do trabalho é que, nos casos analisados, o sistema jornalístico se configura em um imbricado jogo de escalas em que as relações de poder expressas nos discursos dos jornais são influenciadas pela proximidade e pelo distanciamento do seu público, suas fontes, seus financiadores e representantes políticos. É nesse cenário que a imprensa registra em suas páginas uma "batalha de memórias", aqui observada em suas dimensões regional e nacional.

Palavras-chave: Jornalismo. Visibilidade. Memória. Chapecó. Oeste catarinense.
\end{abstract}

\section{Spheres of journalistic visibility and power relations: a study about the memory of the West of Santa Catarina in the national and regional press $(1940-1950)$}

\begin{abstract}
:
This paper analyzes how the West region of Santa Catarina, Brazil, was portrayed in the regional and national press, based on two news events that occurred in 1948 and 1950. Both covers (on the smuggling of wood and on a lynching) deal with themes that put in contrast perspectives of order, progress, backwardness and marginality. The spheres of visibility of journalism are understood here in the plural, focusing on two of them: that of journalism of proximity and that based on journalism of distance. The theoretical-methodological basis of the research combines documentary, bibliographic and content analysis. The main conclusion of the paper is that, in the cases analyzed, the journalistic system is composed for an imbricated play of scales in which the power relations expressed in the discourses, presents in the newspapers, are influenced by the proximity and the distancing of its public, its sources, its financiers and political representatives. It is in this scenario that the press registers in its pages a "battle of memories", observed here in its regional and national dimensions.
\end{abstract}

Keywords: Journalism. Visibility. Memory. Chapecó. West of Santa Catarina.

\section{Esferas de visibilidad periodísticas y relaciones de poder: un estudio sobre la memoria del Oeste de Santa Catarina en la prensa nacional y regional (1940-1950)}

\footnotetext{
${ }^{1}$ Doutoranda do Programa de Pós-Graduação em Jornalismo da Universidade Federal de Santa Catarina (Posjor-UFSC) e integrante do Grupo de Pesquisa Jornalismo, Cultura e Sociedade. E-mail: marcionize@hotmail.com.

${ }^{2}$ Doutor em Comunicação e Informação, professor adjunto vinculado ao Departamento de Jornalismo da UFSC, membro permanente do Programa de Pós-Graduação em Jornalismo (Posjor-UFSC) e integrante do Grupo de Pesquisa Jornalismo, Cultura e Sociedade.E-mail: locatelli.jor@gmail.com.
} 


\begin{abstract}
Resumen:
Este trabajo analiza cómo la región Oeste de Santa Catarina, Brasil, fue retratada en la prensa regional y nacional a partir de dos hechos noticiosos ocurridos en 1948 y 1950. Ambas coberturas (sobre el contrabando de madera y sobre un linchamiento) tratan de temas que ponen en confrontación perspectivas de orden, progreso, retraso y marginalidad. Las esferas de visibilidad del periodismo son aquí comprendidas en el plural, con enfoque en dos de ellas: la del periodismo de proximidad y aquella basada en el periodismo de distanciamiento. La base teórico-metodológica de la investigación combina el análisis documental, bibliográfico y de contenido. La principal conclusión del trabajo es que, en los casos analizados, el sistema periodístico se configura en un imbricado juego de escalas en el que las relaciones de poder expresadas en los discursos de los periódicos son influenciados por la proximidad y el distanciamiento de su público, sus fuentes, financiadores y representantes políticos. Es en ese escenario que la prensa registra en sus páginas una "batalla de memorias", aquí observada en sus dimensiones regional y nacional.

Palabras clave: Periodismo. Visibilidad. Memoria. Chapecó. Oeste de Santa Catarina.
\end{abstract}

\title{
As esferas de visibilidade jornalísticas ${ }^{3}$
}

A proposta deste artigo é analisar como a região Oeste de Santa Catarina, Brasil, foi retratada na imprensa regional e nacional a partir de dois fatos noticiosos ocorridos em 1948 e 1950, sobre o contrabando de madeira e sobre um linchamento, que tratam de temas que colocam em confronto perspectivas de ordem, progresso, atraso e marginalidade. Esse objetivo se justifica a partir da compreensão do espaço que o jornalismo ocupa nas sociedades contemporâneas e da relação entre os discursos e a legitimação de identidades regionais.

O contexto cultural do qual o jornalismo é derivado, e que também alimenta, é historicamente constituído e compartilhado em um determinado espaço, mesmo que as temporalidades e espacialidades tenham se reconfigurado com as redes digitais (CAMPONEZ, 2002; FIDALGO, 2004; AGUIAR, 2016). Contemporaneamente, dada a complexidades das estruturas sociais e das sociedades de maneira geral, grande parte das trocas simbólicas, que constituem a própria essência da cultura e da identidade, ocorre pela mediação dos veículos de comunicação.

No ecossistema dos media, o jornalismo se desenha como uma forma de troca simbólica específica, baseada em regras e princípios construídos social e historicamente, que determinam uma esfera social particular: a da visibilidade jornalística (MAIA, 2008; GOMES; MAIA, 2008). Essa compreensão tem raízes no modelo habermasiano

\footnotetext{
${ }^{3}$ Algumas considerações sobre este trabalho foram apresentadas no GP Geografias da Comunicação do XVI Encontro dos Grupos de Pesquisas em Comunicação, evento componente do XXXIX Congresso Brasileiro de Ciências da Comunicação, realizado em São Paulo-SP em setembro de 2016; também no $14^{\text {o }}$ Encontro Nacional de Pesquisadores em Jornalismo, promovido pela Sociedade Brasileira de Pesquisadores em Jornalismo (SBPJor), realizado em Palhoça-SC, em novembro de 2016. O texto aqui apresentado aproveita alguns elementos desses dois trabalhos, mas amplia a discussão teórica e empírica. A pesquisa da qual deriva esta análise contou com apoio da Coordenadoria de Aperfeiçoamento de Pessoal de Nível Superior (Capes), por meio do financiamento de bolsa de estudos de mestrado.
} 
de esfera pública e na ideia de deliberação pública, derivada da concepção de democracia deliberativa.

O modelo proposto por Habermas (1997) em seus estudos mais atuais ${ }^{4}$ prevê a sociedade baseada em sistemas e mundo da vida. Esses vários sistemas (ou esferas) e subsistemas são distintos, mas, ao mesmo tempo, interdependentes. "Cada qual com seu conjunto de instituições típicas, suas lógicas, seus propósitos, suas formas de manutenção e atribuição da legitimidade" (MAIA, 2008, p. 65).

Em Direito e Democracia, Habermas (1997, p. 92, grifos do autor) explica que "a esfera pública pode ser descrita como uma rede adequada para a comunicação de conteúdos, tomadas de posição e opiniões; nela os fluxos comunicacionais são filtrados e sintetizados, a ponto de se condensarem em opiniões públicas enfeixadas em temas específicos". A esfera pública é, então, entendida como "qualquer encontro que não se limita a contatos de observação mútua, mas que se alimenta da liberdade comunicativa que uns concedem aos outros (...)" (HABERMAS, 1997, p. 93). Trata-se de uma esfera pública discursiva e abstrata, como resultado de uma escala de interação social na qual o público não está mais materialmente reunido. Com isso há "uma perda de contato com os contextos densos das interações básicas, apresentando como contrapartida o ganho de amplitude e de inclusão" (GOMES; MAIA, 2008, p. 92).

Para Maia, o potencial dos veículos de comunicação está em pré-estruturar a esfera pública, promovendo um diálogo público generalizado que informa e reconstitui os espaços de discussão não-midiáticos, os fóruns e as esferas públicas locais (MAIA, 2008, p. 18-19). Embora o sistema midiático tenha características próprias, ele não se isola dos demais, já que é permeável. Além disso, possui estratificações internas, subsistemas. Aproximando mais a lupa, portanto, localiza-se o subsistema do jornalismo que, embora possa ser considerado integrante dos media, possui características e dinâmicas particulares que o tornam um espaço ainda mais específico.

Essas particularidades podem ser definidas em, ao menos, duas dimensões. A primeira vincula essa diferenciação entre o espaço ocupado pelos jornalistas - em relação aos demais comunicadores - ao contrato social tácito estabelecido com o público, que é expresso por meio do reconhecimento de sua legitimidade, ou seja, de sua "utilidade (...) no quadro de uma sociedade pluralista e democrática" (BERNIER,

\footnotetext{
${ }^{4}$ Essa consideração parece necessária no contexto de pesquisa brasileiro, tendo em vista que muitos dos diálogos travados com a obra de Habermas se baseiam no quadro teórico desenvolvido em Mudança Estrutural da Esfera Pública (1984), embora o próprio autor tenha reformulado inteiramente alguns pontos em textos posteriores.
} 
2004 , p. 15 , tradução nossa) ${ }^{5}$. A outra dimensão diz respeito ao ethos profissional que se constitui, conforme Traquina (2012, p. 128), “de ideologias justificativas em que é claramente esboçada uma identidade profissional, isto é, um ethos, uma definição de uma maneira de como se deve ser (jornalista)/estar (no jornalismo)".

A característica de legítimo portador dos discursos baseados na verossimilhança com a realidade tem potencial para colocar o jornalismo em local privilegiado na préestruturação da esfera pública, por meio da promoção da visibilidade de acontecimentos sociais e do fomento do debate público. Por esse motivo pode-se falar de esferas de visibilidade do jornalismo. Sugere-se o enunciado no plural porque, dada a diversidade do ambiente jornalístico, é muito difícil falar em uma instituição única (BUCCI, 2008, p. 50) ${ }^{6}$. O mais realista é apontar critérios básicos que definem os limites do que se pode considerar jornalismo, fronteiras dentro das quais se observa certa diversidade.

Uma das categorizações possíveis do jornalismo que segue os moldes daquele que se convencionou chamar de hegemônico (mainstream) ${ }^{7}$ diz respeito ao grau de proximidade com suas fontes, seu público e seus financiadores. Esse é um dos elementos que permitem a distinção entre, por exemplo, jornalismo local, regional e jornalismo nacional.

Neste trabalho optou-se por explorar o conceito de jornalismo de proximidade, de Camponez (2002), tendo em vista que esse viés transcende os marcos geopolíticos.

Defendemos uma definição de jornalismo regional a partir do conceito de pacto comunicacional realizado no contexto de comunidades de lugar - isto é, comunidades que se reconhecem com base em valores e interesses construídos e recriados localmente, a partir de uma vivência territorialmente situada - e onde intervêm critérios como o espaço geográfico de implantação do projecto editorial; o lugar de apreensão, recolha e produção dos acontecimentos noticiados; o espaço privilegiado de difusão da informação; o tipo de conteúdos partilhados e de informação disponibilizada; enfim, a definição dos públicos (CAMPONEZ, 2011, p. 36-37).

\footnotetext{
5 "La légitimité est la reconnaissance sociale de l'utilité du journalisme dans le cadre d'une société pluraliste et démocratique" (BERNIER, 2004, p. 15).

6 "Um sintoma da precariedade da cultura política nessa matéria [lugar da imprensa] aparece quando algumas autoridades emitem juízos condenatórios generalizantes sobre a imprensa ou, como às vezes dizem, a "grande mídia". (...) pecam pelo primarismo de considerá-la um corpo uno, indivisível, orientado em bloco (...)" (BUCCI, 2008, p. 50).

${ }^{7}$ No contexto brasileiro os veículos jornalísticos hegemônicos, que alguns autores também chamam "de referência", são caracterizados por se constituírem como empresas privadas, financiados majoritariamente por meio de verbas publicitárias, que se autodefinem a partir de valores clássicos atribuídos ao jornalismo, como o de divulgar fatos verdadeiros, de maneira objetiva e imparcial.
} 
Portanto, no caso dos veículos de comunicação regionais e locais, "a proximidade assume um significado próprio, marcante da sua especificidade e da sua identidade" (CAMPONEZ, 2011, p. 36). Essas considerações são complementadas pela observação de Peruzzo (2003, p. 67) acerca do aspecto relacional dessas esferas: "Tanto o local como o regional só podem ser compreendidos na relação de um com o outro, ou deles com outras dimensões espaciais, como o nacional e o global".

Cabe ainda pontuar que a proximidade, mesmo quando se constitui como elemento da própria identidade do jornal, carrega consigo um problema normativo. É que, sob o prisma ético e deontológico, "o valor dominante é o do distanciamento" (CAMPONEZ, 2011, p. 37). Segundo o autor, essa forma de compreender o jornalismo deriva da história desses valores, que desde meados do século XIX se desenham em torno da ideia dominante "da objetividade".

Essa perspectiva também é abordada por Ijuim (2014) em ensaio no qual relaciona o paradigma científico dominante ao fazer jornalístico. Para ele, a configuração do jornalismo hegemônico na contemporaneidade "aconteceu no clima e na circunstância do pensamento científico moderno", ou seja, teve influência da racionalidade científica. Por um lado, isso contribuiu para a evolução das práticas jornalísticas, permitindo uma produção de notícias mais ágil, com maior abrangência e baseada em critérios mais rigorosos de apuração e checagem de dados; por outro, o autor aponta para uma ênfase nas consequências e para uma separação entre sujeito e objeto que tem como resultado a "coisificação" de fenômenos sociais, a exclusão e a desumanização (IJUIM, 2014, p. 9-10).

A ideia do distanciamento do pesquisador daquilo que estuda, transposta para o distanciamento do jornalista dos fatos que noticia, deve ser compreendida em sua ambiguidade. "Se o rigor científico objetiva os fenômenos e os degrada caricaturizando-os - também a imprensa [em muitas situações], ao invés de narrar a contemporaneidade, caricaturiza e degrada o valor humano que move a realidade social" (IJUIM, 2014, p. 10).

O caminho do meio parece ser o que Camponez (2011, p. 44) descreve a partir das leituras de Desroches e Abel, Levinas, Kierkegaard e Ricoeur: "A ética da proximidade não pode deixar de fazer uma economia da distância: nem demasiado perto, que não permita ver, nem demasiado distante, que não permita o reconhecimento das diferenças". 
Essa explanação aponta que no jornalismo - assim como no conceito mais recente de esfera pública habermasiana -, se é possível falar de uma esfera de visibilidade, deve-se levar em consideração que em sua composição há subdivisões, subsistemas, ou seja, múltiplas outras esferas de visibilidade, também jornalísticas, com suas peculiaridades e dinâmicas próprias. Essas têm, entre seus diversos aspectos, a proximidade e o distanciamento como elementos determinantes de práticas, relações de poder $^{8}$, estratégias comerciais e políticas e, consequentemente, de enquadramentos.

Aqui se pretende analisar, especificamente, as esferas de visibilidade que se baseiam no jornalismo de proximidade, ou seja, da imprensa local e regional, e no que se chamará de jornalismo de distanciamento (imprensa estadual e nacional). O foco são as caracterizações que o discurso jornalístico mobiliza para descrever determinadas regiões, o que se relaciona com o tema da memória e da identidade regional. Nesse ponto, a comunicação se torna fundamental porque tanto a memória como a identidade se configuram a partir do discurso, da narração (MARTíN-BARBERO, 2002; BHABHA, 2000; MARINAS, 1995).

Na concepção aqui adotada, a identidade é uma categoria que está relacionada com a memória (POLLAK, 1992). Preservar a memória, ou as memórias, é uma das características dos veículos jornalísticos, especialmente da imprensa. A seleção do que preservar e do que esquecer se dá no bojo de relações de poder e é um gerador de poder, tendo em vista que a memória é ativada como legitimadora de determinadas tradições e identidades. Nesse sentido, os atores com mais poder impõem uma versão da história, processo descrito por Veyrat-Masson e Blanchard (2010) como uma "guerra de memórias". Esses mesmos pesquisadores apontam que a midiatização da sociedade é um aspecto central do debate sobre essa batalha, que envolve rememoração e esquecimento.

$\mathrm{Na}$ interpretação de Pollak, "a memória é um elemento constituinte da identidade, tanto individual como coletiva", porque é um fator importante do "sentimento de continuidade e de coerência de uma pessoa ou de um grupo em sua reconstrução de si” (POLLAK, 1992, p. 204). Construções e reconstruções que são marcados temporal e espacialmente.

\footnotetext{
${ }^{8}$ De modo corrente e no sentido proposto neste artigo, poder indica capacidade ou possibilidade de agir, de produzir efeitos sobre homens, objetos e fenômenos da natureza. Aqui o poder que interessa analisar e trabalhar está no âmbito da política, é o que uma pessoa ou grupo exerce sobre o outro ou os outros. Weber (1984, p. 43) define poder como a "probabilidade que um ator em uma relação social esteja em posição de levar a efeito a sua vontade, independente da base em que essa probabilidade se assenta".
} 
Esses pressupostos teóricos embasaram o estudo que se apresenta a seguir. A base teórico-metodológica da pesquisa combina a análise documental, bibliográfica e de conteúdo. O material analisado foi coletado por meio de uma pesquisa no banco de dados da Hemeroteca Digital Brasileira, complementada por textos localizados na Biblioteca Pública de Santa Catarina.

$\mathrm{Na}$ busca digital, por meio do sistema da Hemeroteca Nacional, foram utilizadas como palavras chave "Chapecó" e "Xapecó". Isso porque, na época estudada, praticamente toda a região Oeste de Santa Catarina pertencia a esse município, cujo nome aparecia com as duas grafias apontadas. Em um primeiro momento foi feita uma análise qualitativa e quantitativa para avaliar quais episódios noticiosos ganharam maior visibilidade no período de 1940 a 1950. Dessa maneira, foram identificados os casos do contrabando de madeira e do linchamento. Sobre o contrabando de madeira foram localizados sete textos jornalísticos em 1948 e 1949, nos jornais Diário da Noite (situado no Rio de Janeiro, integrante da rede dos Diários Associados), Diário Carioca (matutino que circulou entre 1930 e 1974) e Jornal d'Oeste (de Chapecó). Além desses, no livro escrito pelo jornalista Zedar Perfeito da Silva (1950), há vários textos e reproduções de discursos que rebatem as notícias divulgadas estadual e nacionalmente.

Já em relação ao caso do linchamento foram localizadas 22 notícias, reportagens e artigos opinativos, datados de 1950, 1951 e 1953. Esses textos foram divulgados nos jornais Diário da Noite, Folha da Manhã (matutino situado em São Paulo que, mais tarde, foi integrado à Folha da Tarde e à Folha da Noite para formar a Folha de S. Paulo ${ }^{9}$ ), Diário Carioca, O Dia (de Curitiba), O Estado (de Florianópolis), A Voz de Chapecó (com sede no município catarinense que carrega no nome) e na revista Cruzeiro (de circulação nacional).

No presente artigo, é analisada uma amostra composta por seis textos jornalísticos envolvendo o caso do contrabando de madeira (aqui incluído o livro de Silva) e seis sobre o linchamento (inclusive a reportagem publicada na revista Cruzeiro, veículo da rede dos Diários Associados). A seleção dessa amostra levou em consideração os textos mais completos, portanto, as reportagens e notícias longas.

\section{“Aquele não é um município de contrabandistas”!}

\footnotetext{
${ }^{9}$ PAULA; LATTMAN-WELTMAN, 2010.
} 
Em 1948, jornais da rede Diários Associados ${ }^{10}$, no Rio de Janeiro e em Porto Alegre, denunciaram a existência de contrabando de madeira para a Argentina. A via para isso era o Rio Uruguai, o qual marca a divisa entre Santa Catarina e Rio Grande do Sul, Brasil e Argentina, Argentina e Uruguai, desaguando no Rio do Prata. Um dos municípios visitados pelos jornalistas foi Chapecó, em Santa Catarina, com território que nessa época abrangia praticamente todo o Oeste ${ }^{11}$ do Estado.

Figura 1 - Mapa que ilustra a capa do livro Oeste Catarinense (os municípios com os territórios destacados são os que integravam a região tema da obra)

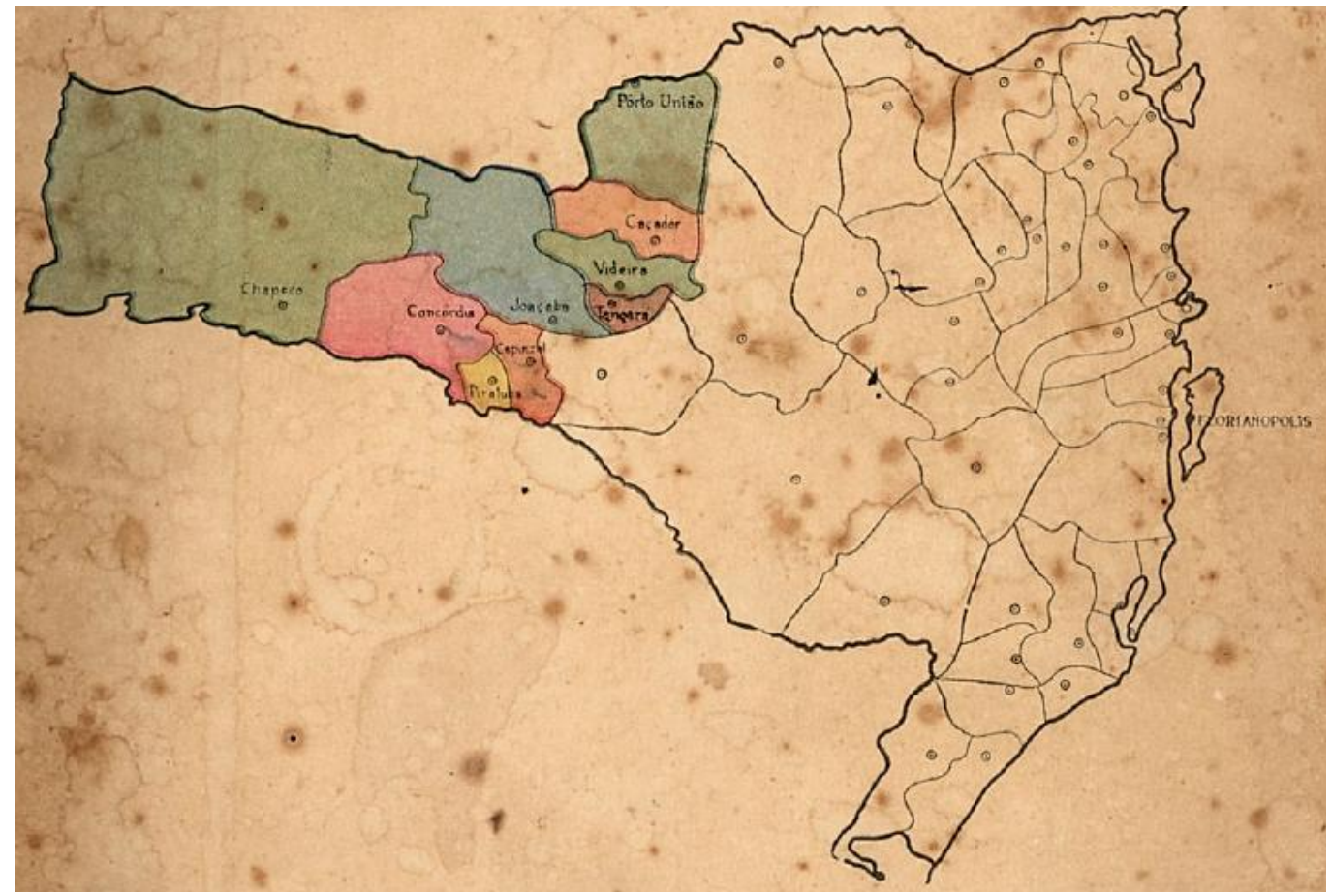

Fonte: Silva (1950)

Na edição de 28 de junho de 1948, o Diário da Noite, jornal da rede dos Diários Associados que circulava no Rio de Janeiro, então a capital do país, anunciava que o governo abriria inquérito para investigar o "vasto contrabando de madeiras para a Argentina". Segundo a nota, a prática envolvia uma "organização clandestina" e provocou a preocupação das autoridades e "da classe produtora" do Rio Grande do Sul, já que estaria causando "sérios prejuízos à economia nacional” (VASTO..., 1948, p. 5).

\footnotetext{
${ }^{10}$ Os Diários Associados, conglomerado fundado por Assis Chateaubriand em 1924, viveram seu apogeu do final da década de 1940 até 1960 . No período de maior expansão, chegaram a reunir 90 veículos de comunicação (BARBOSA, 2007).

${ }^{11}$ Conforme divisão apresentada no site do Governo do Estado, Santa Catarina conta com oito regiões principais: Litoral, Nordeste, Planalto Norte, Vale do Itajaí, Planalto Serrano, Sul, Meio-Oeste e Oeste (GOVERNO DO ESTADO DE SANTA CATARINA, 2016).
} 
As reportagens assinadas pelos jornalistas Jorge Ferreira e Nicolau Leite geraram uma onda de manifestações na imprensa de Chapecó, no Senado Federal e, por consequência, nos veículos de comunicação da capital. Em 5 de junho de 1948, o Diário Carioca registrou em nota sobre o cotidiano da Câmara Alta, que "o que um jornal carioca disse do município de Chapecó (...) não agradou o Sr. Ivo d'Aquino [PSD]”. “Aquele não é um município de contrabandistas” (UMA VITÓRIA..., 1948, p. 2), afirmou ao jornal o senador.

Em seu discurso, registrado na íntegra em livro escrito pelo jornalista Zedar Perfeito da Silva (1950), Ivo d'Aquino disse que ao ler o que os Diários Associados publicaram no Diário de Notícias, de Porto Alegre, e no Diário de S. Paulo, "tem-se a impressão de que Chapecó é composta de gente sem lei nem grei [sic]; que ali predominam a força e o revólver; que autoridades não existem; e que não há a menor coerção, a menor disciplina de ordem política e social" (SILVA, 1950, p. 316).

A principal reclamação dizia respeito à descrição feita nas reportagens publicadas pelo Diário de Notícias e pelo Diário de S. Paulo dos costumes da população local e da afirmação de que Chapecó “é terra sem história, que não tem passado nem tradições" (SILVA, 1950, p. 335). Na capa do Jornal d'Oeste, editado em Chapecó em 12 de junho de 1948, o advogado e ex-promotor da comarcaJosé de Miranda Ramos, que em 1950 se tornaria prefeito do município pelo Partido Trabalhista Brasileiro (PTB), publicou um enfático artigo com críticas à reportagem do Diário de Notícias, de Porto Alegre. No artigo ele relata que, após ler o texto, foi possuído "da mais intensa revolta", uma vez que não podia conceber que "se pudesse escrever contra Chapecó tamanhas monstruosidades" (RAMOS, 1948, p. 1). O trecho a seguir evidencia a indignação:

\footnotetext{
A imaginação do autor da dita reportagem foi por demais fértil, e, pela conclusão a que chegamos, é digna de um assíduo leitor de Edgar Wallace e outros autores do gênero policial, e, também, de um apaixonado admirador de Buffalo Bill. Mas, acontece uma coisa, tais leituras não se adaptam ao nosso Chapecó e as aventuras de Bill, no Oeste dos Estados Unidos, em nada se assemelham aos nossos acontecimentos (RAMOS, 1948, p. 1).
}

$\mathrm{Na}$ contracapa da mesma edição, o jornal manifestou seu repúdio à publicação com a frase impressa no cabeçalho: "Jornal d'Oeste lança o mais veemente protesto contra as referências injuriosas assacadas à população ordeira e laboriosa de Chapecó". Logo abaixo, um longo texto, intitulado "A Assembleia Legislativa Estadual e a 
reportagem sobre Chapecó" (12 jun. 1948, p. 4) relata as discussões geradas a partir do protesto do deputado Cid Loures Ribas (Partido Social Democrático - PSD) acerca do texto jornalístico. Ribas, cabe destacar, era diretor responsável pelo jornal $A \mathrm{Voz} d e$ Chapecó $^{12}$, criado em 1939, e havia atuado como Promotor Público antes de ingressar na política.

Quando Othon d'Eça acompanhou e registrou a expedição do governador Adolfo Konder, em 1929, para o Oeste de Santa Catarina, descreveu a região como "sertão bruto”, “desconhecido”, “matarias vastas e desertas” (D’EÇA, 1992, p. 47ss). Discurso então comum para descrever as regiões interioranas no Brasil. Mas nas décadas que se seguiram essa imagem foi combatida por aqueles que passaram a explorar o espaço, especialmente as empresas colonizadoras, que ao lado da elite madeireira e ervateira, constituíam o núcleo do poder econômico e político. O sistema de exploração da região tinha o apoio do Estado e a imprensa local surgiu nessa imbricada relação de forças.

Em 1948, quando se deu a divulgação das matérias sobre Chapecó, a cidade contava com dois jornais, o Jornal d'Oeste ${ }^{13}$, que tinha ligações com o PTB e a União Democrática Nacional (UDN), então oposição no município; e A Voz de Chapecó, criado por correligionários do PSD, entre os quais o Coronel Ernesto Francisco Bertaso, um dos sócios da principal colonizadorada região, a Colonizadora Bertaso SA. A primeira rádio de Chapecó só seria criada em 1949 (HASS, 2007, p. 178). Esses veículos de comunicação locais possuíam uma capacidade de visibilidade limitada, não comparada a de veículos de comunicação com abrangência nacional, como a dos Diários Associados.

\section{O eldorado do Oeste}

No final da década de 1940 e início de 1950, a representação de uma terra sem lei ainda parecia ter vinculação com a região. No livro O Oeste Catarinense, publicado em 1950, Silva descreve a percepção de parte da população da região litorânea acerca da porção mais próxima da fronteira com a Argentina, que recentemente havia sido reintegrada a Santa Catarina, já que entre 1943 e 1946 essa área compunha o Território Federal do Iguaçu:

\footnotetext{
${ }^{12}$ Essa informação consta no próprio cabeçalho das edições do jornal pesquisadas, datadas de 1950 e 1951.

${ }^{13}$ Há poucas informações sobre o semanário. Na Biblioteca Pública de Santa Catarina existem edições preservadas de 1947 e 1948.
} 
Em fevereiro de 1948, tive a feliz oportunidade de percorrer pela primeira vez o Oeste Catarinense. Fui aconselhado por alguns amigos a levar comigo uma arma de fôgo porque a gente lá de cima, pensavam êles, resolvia tudo no trabuco. Lá, estava situado o nosso far-west ${ }^{14}$ (SILVA, 1950, p. 7, grifo do autor).

Logo na abertura do livro o autor deixa claro que sua intenção, com a publicação, é "mostrar em tôda sua pujança o Oeste Catarinense a Santa Catarina e ao Brasil” (SILVA, 1950, p. 7). Tratava-se, portanto, de dar visibilidade a uma imagem concorrente sobre aquele espaço geopolítico e social. A iniciativa foi comemorada no jornal local, então único a circular no município. Na edição do jornal $A$ Voz de Chapecó, de 12 de março de 1950, consta: "É interessante ressaltar que o livro será editado no Rio de Janeiro e mostrará ao país inteiro a nossa futurosa e rica zona" (OESTE..., 1950, p. $1)$.

O Oeste ao qual Silva se referia em seu livro, cujo mapa estampa a capa (Figura 1, p. 8), abrangia os municípios de Porto União, Caçador, Videira, Tangará, Joaçaba, Capinzal, Piratuba, Concórdia e Chapecó. Esse último se constituía em um município de uma área enorme, quase um terço do território da Suíça (SILVA, 1950, p. 12). Estava estabelecido em um espaço marcado por disputas para a delimitação de suas fronteiras.

O espaço geográfico do oeste catarinense esteve envolvido durante o período colonial numa disputa entre Portugal e Espanha. No século XIX, era disputado pela Argentina e pelo Brasil, com a questão decidida favoravelmente a este em 1895. A mesma área esteve mais tarde em litígio entre Santa Catarina e Paraná, até que, em 1916, o acordo de limites entre os dois estados foi assinado, ficando então os Campos de Palmas sob o controle catarinense (HASS, 2007, p. 22).

Foi nessa área contestada pelos estados do Paraná e Santa Catarina que se deu aquela que é tida como a maior rebelião civil do século XX, a Guerra do Contestado (1912-1916). Embora as batalhas tenham ocorrido, primordialmente, na porção de Santa Catarina, que, segundo divisão usada pelo Governo do Estado, abrange as regiões do Planalto Norte e Meio-Oeste, Renk (1997) aponta o episódio como um estímulo ao modelo de colonização do interior do Estado, especialmente do Oeste. Isso pode ser observado discursivamente, por exemplo, quando alguns políticos da época atribuem o conflito, a mobilização dos "fanáticos", à ausência de um processo de colonização com as “desejadas gentes" (RENK, 1997, p. 49). A região era então ocupada, “essencialmente, por caboclos, posseiros, índios e latifundiários” (HASS, 2007, p. 22).

\footnotetext{
${ }^{14}$ Trechos reproduzidos do original, conforme grafia da época.
} 
A maior parte dessa população não foi contemplada pelo projeto de colonização, tendo em vista a ideologia predominante de que os "trabalhadores", "construtores do progresso e da civilização", eram os descendentes de europeus vindos das colônias velhas do Rio Grande do Sul (RENK, 1997, p. 48). Nesse contexto já complexo, devese adicionar mais um elemento, o mandonismo local, derivado de décadas de coronelismo. Esse aspecto ganhou novos contornos a partir da queda de Getúlio Vargas, em 1945, e a criação de novos partidos. Conforme Hass (2007, p. 195), desde a década de 1940 a região passava por transformações econômicas e sociais que geraram um clima de conflito entre o "velho" e o "novo", seja na política, seja nos costumes. A abertura democrática e a vinda de numerosos migrantes atraídos pela propaganda de "progresso" e "futuro" acirrou esse embate.

\section{Uma nova manchete: o linchamento}

Nem bem o livro de Silva havia saído da gráfica, um novo episódio fez com que o Oeste Catarinense voltasse a se tornar manchete nacional. Trata-se do caso do incêndio da Igreja Matriz de Chapecó, da prisão de quatro acusados e dos seus linchamentos. Na imprensa local, a primeira matéria localizada sobre o tema foi publicada emA Voz de Chapecó em 15 de outubro de 1950, sob o título: Quadrilha de incendiários. O texto ocupou a capa do jornal:

Graças à ação eficiente do Delegado de Polícia desta cidade, sr. Arthur Argeu Lajus ${ }^{15}$, conseguiu na semana finda prender quatro elementos da quadrilha de incendiários que atearam fogo ultimamente na Igreja desta cidade e na serraria do sr. Domingos Baldissera.

Segundo fomos informados, todos confessaram os crimes cometidos (...) (QUADRILHA..., 1950, p.1).

O desfecho da trama foi noticiado no país ${ }^{16}$. Na madrugada do dia 18 de outubro de 1950, dezenas de homens armados tomaram a cadeia do município e lincharam os quatro acusados. Dois dias depois, o Diário da Noiteestampava na capa: "Trucidados os incendiários da Igreja Matriz de Xapecó”. No texto, a íntegra de um telegrama narrando brevemente os fatos: “(...) quatro pessoas recolhidas à cadeia pública local, com prisão

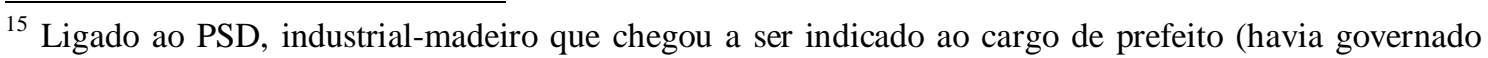
por quase duzentos dias em 1947) e tido como adepto das estratégias de intimidação que caracterizavam o mandonismo local (HASS, 2007).

${ }^{16}$ No livro de Monica Hass (2007) há uma detalhada descrição dos conteúdos divulgados pelos veículos de comunicação locais, regionais, estaduais e nacionais, que são utilizados como fonte para a reconstrução histórica do fato e das redes de poder envolvidas, com influência sobre os veículos de comunicação.
} 
preventiva como culpadas do incêndio ocorrido na Igreja da Matriz, foram trucidadas dentro do recinto das celas e carbonizadas no pátio" (TRUCIDADOS...,1950, p. 1). A nota dizia que o linchamento havia sido levado a cabo por cerca de duzentas pessoas e identificava os mortos: Orlando Lima, Armando Lima, Romano Ruani e Ivo de Oliveira Paim, os dois últimos com antecedentes criminais (TRUCIDADOS..., 1950, p. 1).

No jornal $A$ Voz de Chapecó, o linchamento foi noticiado na capa da edição de 22 de outubro. Com o título "Barbarismo", o texto dizia que uma multidão (de cem a quinhentos homens), vinda do "interior do município", havia assaltado a cadeia pública e "trucidado" quatro detentos. Ao contrário do texto sobre a "quadrilha de incendiários", publicado dias antes, afirmava que apenas dois dos mortos eram acusados do incêndio da Matriz, Ruani e Paim, e que os irmãos Lima estavam presos para “averiguações”. Em determinado trecho dá ênfase às explicações do delegado sobre os motivos de não ter realizado a transferência dos detidos antes da tragédia.

É preciso frisar que o sr. Delegado de Polícia, cidadão Arthur Argeu Lajus, sabedor que os presos estavam ameaçados de assalto, telegrafou ao sr. Secretário de Segurança solicitando permissão para conduzir os detentos para Joaçaba. (...) ficou resolvido conduzirem os presos para Joaçaba na manhã seguinte (BARBARISMO, 1950, p. 1).

Muito diferente é a reportagem de capa da Folha da Manhã, de São Paulo. Com autoria de Carlos de Freitas e fotos de Antonio Pirozzelli, o texto sobre o linchamento ocupa toda a contracapa da edição de domingo, 12 de novembro de 1950, sob o título "Fúria em Xapecó". No texto, o povo da cidade é retratado como ignorante e apegado a misticismos. "A tragédia de Xapecó foi gerada unicamente pela ignorância, própria de uma região atrasada como o oeste catarinense, onde a civilização estacionou (...)”. Também há a informação de que dois dos mortos eram inocentes. O final do texto enfatiza o teor moral e religioso que transpassa todo o texto: “(...) e os próprios matadores, depois de cumprirem pena (...) terão medo de ver com seus próprios olhos a sombra dos 4 homens, galopando num cavalo de fogo, sobre a cidade pecadora" (FREITAS, 1950, p. 9).

Um dia antes, na edição de 11 de novembro de 1950, a revista O Cruzeiro divulgou uma ampla reportagem, assinada por José Leal, com fotos de Flávio Damm, em que repercutiu o linchamento. A imagem principal mostra os corpos amontoados e carbonizados jogados no pátio da delegacia, enquanto uma multidão de curiosos observa. Há ainda fotos e entrevistas com os principais personagens envolvidos na 
tragédia, entre os quais o delegado Artur Argeu Lajus, apontado como um dos principais responsáveis. O texto começa com uma explanação sobre a cidade, bem diferente daquela apresentada na Folha da Manhã.

Chapecó é uma típica cidade madeireira do oeste de Santa Catarina (...). Tem 5 mil habitantes, um grande movimento comercial e sua população é cem por cento católica além de "ordeira e pacífica" como me garantiu o Juiz de Direito local Dr. José Pedro Mendes de Almeida (LEAL, 1950, p. 115).

Já os executores do linchamento são descritos como uma "multidão de fanáticos", orientados por homens de confiança do delegado. No final da reportagem, o jornalista afirma que o linchamento foi "a mais bárbara de todas as chacinas já cometidas no Brasil” (LEAL, 1950, p. $90^{17}$ ).

A repercussão negativa da sucessão de fatos que culminou nas mortes, para a imagem da cidade, foi debatida no jornal local. Em 26 de novembro,A Voz de Chapecó publicou artigo assinado por Tulio Fontoura, diretor do Jornal da Serra, de Carazinho, e do Diário da Manhã, de Passo Fundo, ambas cidades do Rio Grande do Sul. Na opinião de Fontoura, muitos jornais não se limitaram a informar "senão que deturparam dantescamente os acontecimentos". "Neste impulso condenável eles esquecem, muitas vezes, que uma coletividade não responde pelos erros, pela insipiência, vícios e maldades dos que se transviaram do caminho da ordem, do respeito às Leis" (FONTOURA, 1950, p. 1).

Para justificar essas considerações, o linchamento foi descrito por Fontoura como realizado por uma "pequena turba ignorante e incitada, formada em sua maioria por gente do interior no município". Já as notícias e reportagens sensacionalistas teriam atingido "a família, a sociedade digna da cidade de Chapecó" (FONTOURA, 1950, p. $1)$.

\section{Algumas considerações}

As duas pautas analisadas expressam a concorrência entre diferentes enquadramentos ${ }^{18}$ jornalísticos sobre a região Oeste de Santa Catarina, que variaram entre o far-west e a perspectiva de progresso, entre a violência e a ordem. Esse é o contexto a partir do qual se estabeleceu uma narrativa sobre esse espaço geopolítico,

\footnotetext{
${ }^{17} \mathrm{Na}$ revista Cruzeiro era comum que o final das reportagens estivesse em páginas diferentes do bloco principal de textos e imagens.

${ }_{18}$ Aqui, no sentido que Maia (2009, p. 308) atribui ao termo: como "princípios organizadores" ou "esquemas interpretativos".
} 
social e simbólico, com repercussões até os dias atuais ${ }^{19}$. Isso porque, como indicado por Veyrat-Masson e Blanchard (2010, p. 16), a midiatização dos acontecimentos e a consequente rememoração de determinados fatos e esquecimento de outros é uma dimensão da "batalha de memórias".

Aqui, o exercício de análise levou em consideração as dinâmicas, por um lado, do jornalismo de proximidade e, por outro, o de distanciamento, feito a partir de um centro de mediação sobre espaços que lhe são periféricos. No material empírico descrito, essa é uma divisão possível, em que os jornais das grandes cidades trataram a região Oeste catarinense como um espaço distante geograficamente e culturalmente, enquanto os jornais de Chapecó tiveram uma relação de proximidade (nos moldes definidos por Camponez, 2002) com seus leitores, suas fontes e seus financiadores. Como a análise empírica evidenciou, o problema ético dessa proximidade simbiótica se mostra pelo envolvimento dos próprios diretores, fundadores e donos dos veículos de comunicação nos fatos noticiados.

Isso acarreta uma vulnerabilidade dos jornais locais à influência do poder dos grupos próximos. Em ambos os casos analisados, isso ficou evidente. Na cobertura sobre o contrabando de madeira, o poder local se manifestou por meio das lideranças políticas de diferentes partidos. Nesse caso, as divergências das siglas ficaram em segundo plano em prol da defesa da imagem de cidade de gente trabalhadora e ordeira, cidade do futuro, que estava em amplo desenvolvimento.

É verdade que na esfera de visibilidade do jornalismo local a voz presente era fundamentalmente a de uma elite econômica, política e intelectual, e isso independentemente de a que partido se estava vinculado. Em nenhum dos textos citados dos jornais chapecoenses, há indicação de fontes de outros grupos sociais, como das classes populares e de trabalhadores.

Também é importante destacar que as manifestações que conseguiram transpor a barreira da esfera de visibilidade local do jornalismo partiram de políticos com vínculos locais e representação nos legislativos estadual e nacional. É a partir dos legislativos estadual e nacional que a questão teve capacidade de atingir esferas de visibilidade mais amplas, do jornalismo de distanciamento. Portanto, a relação entre poder político e jornalismo pode ser analisada a partir de uma lógica de escalas.

No caso do linchamento ocorrido em Chapecó em 1950, o jornal A Voz de Chapecó, único jornal da cidade nesse período, aderiu à defesa do delegado, o que

\footnotetext{
${ }^{19}$ Sobre esse aspecto, há informações na pesquisa realizada por Bavaresco (2017).
} 
destoou da imprensa nacional que, com seu olhar "de fora", demonstrou maior independência em investigar as responsabilidades pelos crimes. O jornal $A \mathrm{Voz} d e$ Chapecó era ligado ao PSD, partido ao qual o delegado tinha vinculação. Já dois dos mortos, os irmãos Lima, tinham ligações com o PTB (HASS, 2007). Aqui o poder sobre a comunicação local desequilibrou a balança, o que só foi alterado a partir da atuação, dentro do sistema midiático, dos jornais estaduais e nacionais.

Não sendo possível negar a "selvageria" dos fatos, a tentativa, na esfera de visibilidade local, foi de isolar as ações a um determinado grupo, "do interior", marginalizado em relação às elites. Aqui se tem um caso daquilo que se apresentou na explanação teórica: de que as características atribuídas a determinados grupos são, ao mesmo tempo, integradoras e segregadoras. O que fica nas entrelinhas desse discurso é que, embora todo esse grupo seja de oestinos, há aqueles que "são ordeiros" e que “querem o desenvolvimento" da região e há os que não se encaixam nesse perfil. Os últimos, embora citados nos textos, não têm a voz registrada nas páginas dos jornais analisados.

Posto isso, é importante indicar que o distanciamento não parece ter sido solução absoluta para um jornalismo mais plural e que abarque a complexidade dos fenômenos sociais. Nos casos descritos, o que se percebeu é que os jornais mais afastados recorreram com maior frequência a estereótipos e caracterizações generalistas acerca da região, portanto, reiterando as considerações feitas por Ijuim (2014). É preciso destacar que o grau de utilização desses recursos variou significativamente entre os textos de cada um dos veículos de imprensa analisados.

De certa maneira, as duas situações marcam movimentos importantes do jornalismo na permanente "guerra de memórias", descrita por Veyrat-Masson e Blanchard (2010), sobre a região. Nos casos estudados, essa batalha apresenta diferentes elementos em escalas de visibilidade jornalística diversas, o que retroalimenta as caracterizações identitárias do Oeste de Santa Catarina em dimensões que vão do local ao nacional. É na relação desses discursos, e muitas vezes no conflito entre eles, que se solidifica uma memória regional, parte fundamental da definição do que é esse espaço geopolítico e simbólico, ou seja, de uma identidade regional.

\section{REFERÊNCIA BIBLIOGRÁFICA}

A ASSEMBLEIA Legislativa Estadual e a reportagem sobre Chapecó. Jornal d'Oeste, Chapecó, p. 4, 12 jun. 1948. 
AGUIAR, Sonia. Território-rede e as geografias da internet. In: CONGRESSO BRASILEIRO DE CIÊNCIAS DA COMUNICAÇÃO, 39., 2016, São Paulo. Anais eletrônicos... São Paulo: Intercom, 2016. Disponível em: <http://portalintercom.org.br/anais/nacional2016/resumos/R11-1925-1.pdf>. Acesso em: 17 set. 2016.

BARBARISMO. A Voz de Chapecó, Chapecó, p. 1, 22 out. 1950.

BARBOSA, Marialva. História cultural da imprensa (1900-2000). Rio de Janeiro, Mauad X, 2007.

BAVARESCO, Marcionize Elis. Jornalismo, identidade regional e controvérsias públicas: a definição simbólica do Extremo Oeste catarinense na imprensa. 2017. 269 f. Dissertação (Mestrado em Jornalismo) - Universidade Federal de Santa Catarina, Florianópolis, 2017.

BHABHA, Homi K. DissemiNation: time, narrative, and the margins of the modern nation. In: BHABHA, Homi K. (Org.). Nation and narration. New York: Routledg, 2000, p. 291-322.

BERNIER, Marc-François. Éthique et déontologie du Journalisme. Saint-Nicolas (Québec): Les Presses de l’Université Laval, 2004.

BUCCI, Eugênio. A imprensa e o dever da liberdade: a responsabilidade social do jornalismo em nossos dias. In : CANELA, Guilherme (Org.). Políticas públicas sociais e os desafios para o Jornalismo. São Paulo: Andi/Cortez Editora, 2008, p. 46-62.

CAMPONEZ, Carlos. Jornalismo de proximidade:rituais de comunicação na imprensa regional. Coimbra: Minerva Coimbra, 2002.

Jornalismo regional: proximidade e distanciações. Linhas de reflexão sobre uma ética da proximidade no jornalismo. In: CORREIA, João Carlos (Org.). Ágora Jornalismo de proximidade: limites, desafios e oportunidades. Covilhã, Portugal: LabCom/UBI, 2011, p. 35-47. Disponível em: <http://www.labcomifp.ubi.pt/ficheiros/20121224-agora_ebook.pdf>. Acesso em: 22 maio 2016.

D'EÇA, Othon. Aos espanhois confinantes. Florianópolis: FCC: Ed. da UFSC, 1992.

FIDALGO, António. Jornalismo online segundo o modelo de Otto Groth. Pauta Geral, Salvador, 2004. Disponível em: <http://www.bocc.ubi.pt/pag/fidalgo-groth-jornalismoonline.pdf>. Acesso em: 25 ago. 2015.

FONTOURA, Tulio. Sensacionalismo corruptor. A Voz de Chapecó, Chapecó, p. 1, 26 nov. 1950.

FREITAS, Carlos de. Furia em Xapecó. Folha da Manhã, São Paulo, p. 9, 12 nov. 1950.

GOMES, Wilson; MAIA, Rousiley C. M. (Org.). Comunicação e democracia: 
problemas \& perspectivas. São Paulo: Paulus, 2008.

GOVERNO DO ESTADO DE SANTA CATARINA. Conheça SC. Geografia. [Site]. Disponível em: <http://www.sc.gov.br/index.php/conhecasc/geografia >. Acesso em: 4 jul. 2016.

HABERMAS, Jürgen. Direito e democracia: entre facticidade e validade, v 2. Rio de Janeiro: Tempo Brasileiro, 1997.

1984.

Mudança estrutural da esfera pública. Rio de Janeiro: Tempo Brasileiro,

HASS, Monica. O linchamento que muitos querem esquecer. 2. ed. rev. Chapecó: Argos, 2007.

IJUIM, Jorge Kanehide. Ciência e Jornalismo: apontamentos sobre as ideias de Boaventura de Sousa Santos para a compreensão do Jornalismo. Revista Ação Midiática: Estudos em Comunicação, Sociedade e Cultura, Curitiba, n. 7, 2014. Disponível em: <http://revistas.ufpr.br/acaomidiatica/article/view/36297>. Acesso em: 5 abr. 2016.

LEAL, José. O linchamento de Chapecó. O Cruzeiro, Rio de Janeiro, p. 90, 114-120, 11 nov. 1950.

MAIA, Rousiley (Coord.). Mídia e deliberação. Rio de Janeiro: FGV, 2008.

MAIA, Rousiley. Debates públicos na mídia: enquadramentos e troca pública de razões. Revista Brasileira de Ciência Política, Brasília, n. 2, p. 303-340, jul./dez. 2009. Disponível em: <http://periodicos.unb.br/index.php/rbcp/article/view/6585>. Acesso em: 10 fev. 2016.

MARINAS, José Miguel. La identidad contada. Destinos del relato al filo del milenio. Archivos de la Filmoteca, Valencia, n. 21, p. 75-87, out. 1995. Disponível em: <http://www.archivosdelafilmoteca.com/index.php/archivos/article/view/335/335>.

Acesso em: 4 out. 2016.

MARTÍN-BARBERO, Jesús. Tecnicidades, identidades, alteridades: des-ubicaciones y opacidades de la comunicación en el nuevo siglo. Quince Años de Dia-Logos. Diálogos de la Comunicación, Lima, n. 64, p. 8-24, 18 nov. 2002. Disponível em: $<$ http://dialogosfelafacs.net/wp-content/uploads/2015/64/TECNICIDADESIDENTIDADES-ALTERIDADES.pdf $>$.

OESTE Catarinense. A Voz de Chapecó, Chapecó, p. 1, 12 mar. 1950.

PAULA, Christiane Jalles de; LATTMAN-WELTMAN, Fernando. Dicionário Histórico-Biográfico Brasileiro - DHBB. 3. ed. Rio de Janeiro: CPDOC-FGV, 2010. Disponível em: <http://cpdoc.fgv.br/acervo/dhbb>. Acesso em: 23 abr. 2017. 
PERUZZO, Cicília M.K. Mídia local e suas interfaces com a mídia comunitária. Anuário UNESCO/UMESP de comunicação regional. São Bernardo do Campo: Cátedra Unesco/ UMESP, 2003, p. 52-78.

POLLAK, Michael. Memória e identidade social. Revista Estudos Históricos, Rio de Janeiro, v. 5, n. 10, p. 200-212, 1992. Disponível em: <http://bibliotecadigital.fgv.br/ojs/index.php/reh/article/view/1941/1080>. Acesso em: 17 ago. 2016.

QUADRILHA de incendiários. A Voz de Chapecó, Chapecó, p. 1, 15 out. 1950.

RAMOS, José de Miranda. Notas e Comentários. Jornal d'Oeste, Chapecó,p. 1,12 jun. 1948 .

RENK, Arlene. A luta da erva: um ofício étnico no Oeste Catarinense. Chapecó: Grifos, 1997.

SILVA, Zedar Perfeito da. O Oeste catarinense. Rio de Janeiro: Laement, 1950.

TRAQUINA, Nelson. Teorias do Jornalismo: porque as notícias são como são, v. 1. 3. ed. rev. Florianópolis: Insular, 2012.

TRUCIDADOS os incendiários da Igreja Matriz de Xapecó. Diário da Noite, Rio de Janeiro, p. 1, 20 out. 1950.

UMA VITÓRIA do senador Mario Ramos. Diário Carioca, Rio de Janeiro, p. 1, 5 jun. 1948.

VASTO contrabando de madeiras para a Argentina. Diário da Noite, Rio de Janeiro, p. 5, 28 jun. 1948.

VEYRAT-MASSON, Isabelle; BLANCHARD, Pascal. Les guerres de mémoires: la France et son histoire. Paris: La Decouverte, 2010.

WEBER, Max. Economia y Sociedad. México: Fondo de Cultura Económica, 1984.

Submetido em 30.11.2016

Aceito em 29.10.2017 